\title{
The Predicament and Countermeasures of Talents Attraction in Independent Colleges Jing-Chen $\mathrm{ZHOU}^{\mathrm{a}}$, Li-Kun WEI ${ }^{\mathrm{b}}$ \\ Jincheng College of Sichuan University

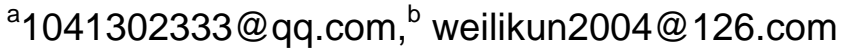

Keyword: Independent colleges, Talents attracting, Floating teachers.

\begin{abstract}
With the popularization of higher education, the important part of it, independent colleges have attracted extensive attention of our society. Especially the problem on the floating teachers and attraction deficiency of talents. Empirical study and comparative study has been made of the capital source, management institutions, professional title set-ups, school culture, brand building between public schools and independent colleges(JC college of Sichuan University), and put forward own opinion to how to improve talents attracting of independent colleges.
\end{abstract}

In 23rd April 2013, some opinions about "standard and strengthen the new system and mode of attempting to run independent colleges in ordinary universities” published by China's Ministry of Education. It defined that independent colleges are the secondary colleges, undergraduate level, and established by ordinary universities. And then in 2008, Ministry of Education published "the establishment and management method of independent colleges" defined that independent colleges are the ordinary colleges established by the ordinary universities which set undergraduate or above, cooperate with the none-government institutes or person, with no state's financial resources. Independent colleges is an important part of higher education, also the welfare of the country.

The first independent college, City College of Zhejiang University, was established by Ministry of Education in 1999. According to the "bulletin of statistics for Chinese educational cause development", the number of independent school reached to 266, and by the time of $21^{\text {st }}$ February 2017, the number of it reached 275. From the development of independent school, it can be seen that independent school always in a process of exploration. In terms of the particularity nature, the difficulties of how to attract and retain talents has been appeared. It evoked enormous scholars to solve this problem from different points, and the mainly achievement are the followings:

\section{Analyzing the Flight Rate from Objective Factors Such as Salary and Welfare, Motivation Mechanism and Nation Policies and So On.}

The cause of high flight rate of independent schools' teachers is congenital, had no supports of national financial. Chen Xiao-li refers to that because the salary and welfare has no competition with the ordinary universities, and teachers had unclear orientation. Zhang Zheng thinks that caused by the singleness and deficiency of motivation mechanism, meanwhile he put forward that make the method of recruitment more variety and standardize the promotion paths can help to retain talents.

\section{Analyzing the Reason of Loss of Teachers from Subjective Factors Such As the Psychological Contract}

Wang Fang consider that the loss of teachers is related to the psychological contract between independent schools and teachers. Including the expectation between teachers and colleges, their understandings on obligations and rights in this employment relationship, commitments made by colleges and the satisfaction of teachers. Zi-Yuan He, Mei-ZiCaiand Cui Can pointed that the high flight rate caused by the loss of belonging, satisfaction and the sense of direction. They proposed that humanism management mechanism should be established by the colleges. 


\section{Analyzing the Reason of Loss of Teachers from Other Factors Such as school Culture, Scientific Research Environment and Teachers' Structure}

Wei-Guang Wei proposed that the reason why independent colleges have problems in retaining talents is the bad scientific research environment, and the lack of hardware. furthermore, independent school always look up the teaching than research, leading to a bad academic environment. And the scientific research staff will go. Hao-Liang Yin proposed that the main reason is the school-running conceptions of colleges is not humanism but take gains as principal. That makes the lack of human care of the school culture. And there are a few prat leading teachers in independent college, so the young teachers can not get enough experience from them. So you can imagine how high the flight rate is.

It is can easily be seen that most of the scholars had researched the loss of talents and how to retain teachers. But the shortcoming is they did not recommend how to attract teachers. This paper basis on empirical study and theoretical research of the fully understand of how to improve talents attracting, and attempt to research how to improve the talents attracting ability of independent colleges systematically.

\section{The Research from the Characteristics of Talents Demand}

\section{Middle-Aged Backbone Teachers are Needed.}

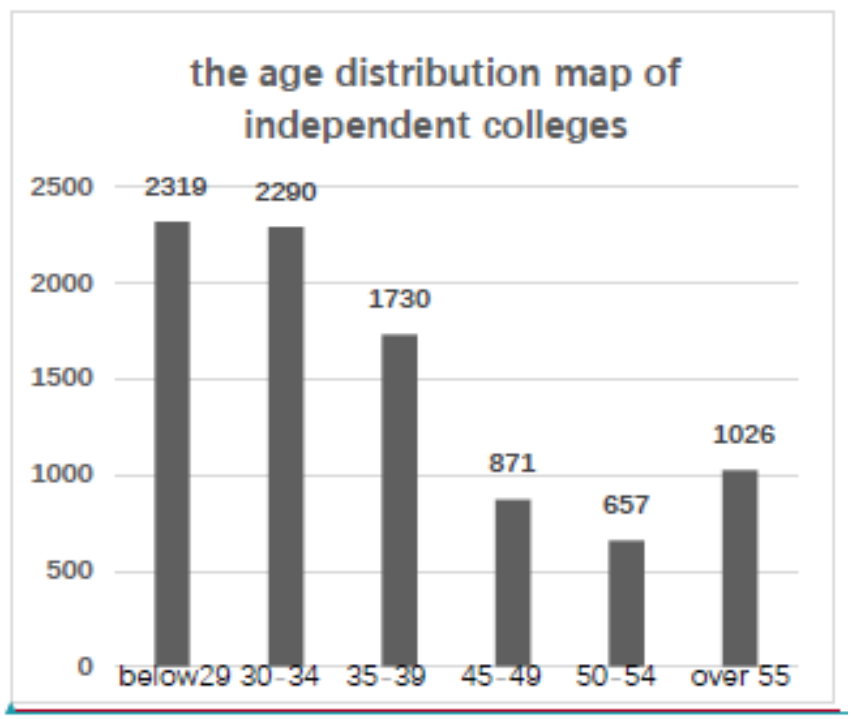

Bar chart 1. Data source : statistical data from Ministry of Education,2016

From the bar chart 1, it can be seen a big part of teachers of independent college are young teachers below 35,and old teachers over 55 near retirement. This formation leads to some problems. For instance, young teachers have little teaching and research experience, and there are always difficult for management. For old teachers, they face the nearly retirement, although they have lots of teaching and researching experience, meanwhile, they have bad body condition. That may cause instability teacher structure. Because of the problems above, independent colleges need more middle-aged backbone teachers to improve the stability of teacher structure.

\section{The New Born Majors' Teachers are Needed.}

The independent colleges had improved depend on the ordinary universities ever. So they didn't have their own special majors, and for attracting more students, independent colleges open plenty of hot majors, such as the big data analysis and e-commercial, but that leads to some problems, like independent schools lack the new born majors' teachers, so they could only employ related teachers from ordinary universities. So the stability of prat time teachers is not so good. From the above reasons, we can easily come to a decision is that independent colleges should have their own 
special majors related teachers.

\section{The Reason of Talent Drain Phenomenon in Independent Colleges}

With the macroscopic reasons and the microscopic reasons, the high rate of talent drain and the shortcomings in talent attraction always be concerned. Now we have made the following summaries: the level of national policy, the level of school management, the level of individuals and the level of students and market.

\section{The National Financial Support is not in Place.}

The government only give the legitimacy of regulations and the rationality of policy to independent colleges, in "Setting and Management Method of Independent Colleges (the No26. Order of Education Ministry)". The Article 2 of it clearly stated that independent colleges use the fund of non-government, that means China only give the policy admit, but no financial support. Government allowed alumni of independent colleges to donation for them. But those colleges are both very young, so almost no excellent alumni donated to them. That lead to the shortage of construction fund.

Most fund of the independent colleges came from tuition fee. Like JC college, a student will pay around 15000 yuan a year. Although independent colleges have right to add tuition fees, considered the problem of the source of students, this method can be hard to carry out. Due to the fund shortage, hardware facilities always in a low level. Like in JC college, some facilities like computers have never been changed since 2005. Teachers always complain about that when they go to class. So that make the teaching experience not satisfaction.

\section{And there are Some Differences in Personnel System.}

Nowadays the independent college selected faculty employment system. Because of the system problem of independent colleges, the teachers of independent college are not into the government compilation. Carrying out personnel representation and contract system management. Meanwhile, setting up internal subsidy, distributing that to teachers according to teaching work amount, teachers and colleges pay the insurance together.

\section{Low Wage and Treatment and Non-Ideal Prospect.}

The marketing operation without fund support from government in independent colleges leads to low wages, and most of teachers in independent colleges are young, they have children to rearing and elders to maintain. And their welfares including endowment insurance and housing funding, are lower than ordinary universities' teachers. That leads to if there are some better choice, teachers in independent colleges will choose to change job.

Some backbone teachers in independent colleges, they are masters or doctors, so they hope they can have some achievements in research projects more or less. But there are some problems. Due to the short established time, low recognition and low research platform, the editors of some periodicals have discrimination to those teachers of independent colleges in China. That means they have no competition in projects application. Independent colleges have no or little research funding supports, and the shortage of scientific research leader, scientific research atmosphere is not strong, and their research equipment is not advanced. Leading to independent colleges have difficult in scientific achievements, and lack of development prospects, so independent colleges can not retain talents.

Independent college, such as JC college, the workload of teachers is relatively large, teachers will provide 15 hours of class every week, and sometimes repeat the same course for multiple majors, plus guide the graduation thesis, graduate internships, social practice, also take the time to do scientific research, each teacher has research indicators, these repeated, cumbersome, heavy tasks make teachers job burnout higher.

Independent college management system is more complicated, JC college, for example, a 
full-time teachers have to complete a higher target per semester, coupled with the high status of administrative post, there are often check administrative staff, if the students had classes, who is late for early departure or absence, there are meets for criticism, so the freedom and respect of teachers can not be guaranteed. According to Maslow's hierarchy of needs theory, such public criticism can not meet the teachers' need of respect and may also lead to the loss of teachers. And the examination cycle is long, such as counselors such administrative positions took a long time to teach, and first of all they have to through general education curriculum teaching, then to choose their favorite classes. Repeated long-term administrative positions will also make thriving young people do not adapt, leading to brain drain.

However, due to the lack of attention and long-term planning of the development prospects of hired teachers in independent colleges, the loss of qualified personnel and the lack of appeal to the top-level teachers make the structure of teachers unbalanced. As can be seen from the figure below, the majority of full-time teachers in independent colleges are intermediate-level titles. Compared with the structure of teachers in ordinary universities, public institutions have $47 \%$ of senior and associate senior teachers, while those in independent colleges Teachers are senior and vice senior titles accounted for only 37\%. (data is shown in pie 1 and pie 2)

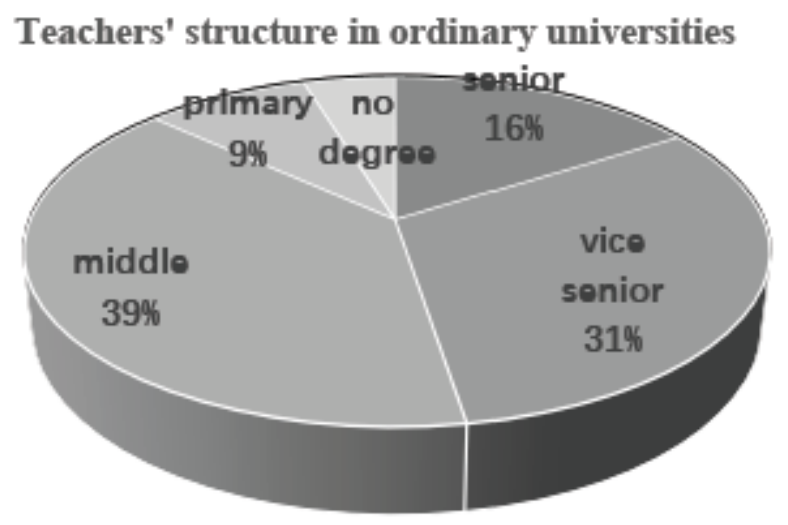

Pie1 data source : $\quad$ statistical data from Ministry of Education,2016

\section{Teachers' structure in independent colleges}

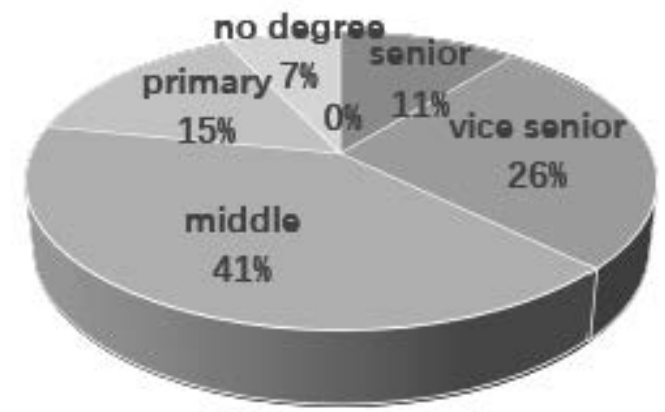

Pie2 data source: statistical data from Ministry of Education,2016

In the 1960s, the push-pull theory put forward by American scholar E.S.Lee pointed out that labor migration is caused by wage differences between immigrants and migrants. Modern push-pull theory holds that in addition to higher income, push-pull factors of migration have better occupation, better living conditions, better education opportunities for themselves and their children, and a better social environment. People are economic people and seeking a better working platform in pursuit of higher economic efficiency can also explain why there is frequent movement of talents in independent colleges. 


\section{Enrollment Insufficiency, the Overall Quality of Students is not High.}

After the State promulgated the "Measures for the Establishment and Management of Independent Colleges" in 2008, independent colleges developed independently from their mother universities, and diploma and degree certificates from independent colleges did not issue the diplomas of their mother colleges and universities. Coupled with college enrollment in recent years and study abroad as a boom, the competitiveness of independent college enrollment also had a huge impact.

And due to discrimination in employment units, resulting in student sources to reduce year by year, reducing the number of applicants, but enrollment increased, resulting in uneven quality of students. School discipline is not good. Many teachers pointed out that no class sitting in the front seat of the class, bow to play mobile phones, late leaving early as a serious phenomenon, the level of students can not keep up the progress of teachers. Especially in recent years, the level of study phenomena is different from that in the past. Part-time teachers in the mother university colleges experience poor teaching experiences in independent colleges, and the teacher's psychology falls seriously, and there is no sense of accomplishment.

In view of the above problems, the author pointed out a few solutions to the problem

\section{Firstly, Get Financial Support.}

Under the guidance of the core values of fairness and impartiality, the state and local governments should implement the same policy as soon as possible for ordinary universities and independent colleges, and provide financial and tax support to independent colleges that have outstanding performance and exemplary values. For example, the five-star JC college Independent colleges each year bring many financial benefits to Sichuan Province and cultivate many outstanding talents. Then the government should provide corresponding financial support in the career development, capital arrangement, major education and reform projects, professional construction and practical training base. For example, Japan passed the "Private School Rehabilitation Help Act," which states that the state can provide financial support to private schools in order to maintain fairness in the distribution of social teaching resources. Of course, the support includes the fairness of teachers' scientific research platform so that teachers in independent colleges and teachers in public universities can be truly equal in applying for scientific research projects. We hope that all departments can call on the government to conduct experiment programs. This solves the most important issue of the development of independent colleges and attracts talented people - the source of funding, so that teachers do not have any worries. It also enhances the college's hardware and gives teachers a good teaching experience. With advanced teaching equipment to enable students to also have access to more cutting-edge teaching methods

\section{Secondly, Reform Existing Pay Performance Management Methods}

At the same time, institutional reform within the colleges is also very important. In colleges, according to the conditions and development status of their own schools, we should improve the wage and salary system and welfare system, make up for the pension insurance and housing provident fund, and establish reasonable and fair distribution System, first of all to ensure the fairness of internal wages, and then try to narrow the wage gap with other ordinary universities' teachers. At the same time, giving teachers a good platform for scientific research, increase investment in research project funds, the introduction of advanced equipment, so that teachers have a good research environment.

\section{Third, Developing a Variety of Channels to Attract High-Quality Talent.}

Independent colleges should attract more talents and there is no doubt that they should establish good cooperative relations with their mother universities so that some outstanding teachers from their mother universities will be put into teaching in independent colleges. They can hire retired vice senior and senior professors, play a "band" role. For example, in late September of this year, the Ministry of Education, the Ministry of Finance and the National Development and Reform Commission issued the Circular on Announcement of the List of Top Universities and Construction 
Disciplines in World-Class Universities and Top-Level Disciplines. "Qinghai University was nominated as a first class university. This is closely linked with the cooperation with Tsinghua University. On June 13, 2001, the Ministry of Education started the matchmaking support for colleges and universities in the western region and Tsinghua University counterparts to support Qinghai University. This brought a new idea and development train of thought for running a school for Qinghai University. Of course, also attracted many talents to join the construction of Qinghai University, completed from "blood transfusion" to "blood forming" process.

Independent colleges can not rely solely on teachers at their mother universities. They need to attract talents through multiple channels. For example, in addition to the full-time teachers, there are many part-time teachers in the JC college. First, they are serving teachers at universities such as SC university, and secondly, managers and technicians who enrich their work experience in enterprises and institutions, such as the Institute of Business Administration, 90\% of teachers are composed of this part of staff; Hiring teachers is not limited to full-time teachers. For example, experienced professional managers who go to school may change their inherent stereotypes about independent colleges, reduce their employment discrimination, increase their employment rate, improve the competitiveness of their students and raise their talented people Attractive.

\section{Forth, Constructing the Campus Culture, Shaping the Campus Brand.}

The campus brand is full of independent college education philosophy, teaching characteristics, school rules and motto, as well as the initial establishment of the school's first generation leaders determination. Build a good campus culture, establish brand awareness can make students have a good learning outlook, improve the sense of accomplishment of teachers. The construction and promotion of the campus brand will undoubtedly improve the teachers' pride and enthusiasm, establish a good social image and attract more outstanding talents.

Independent colleges should based on their own unique needs and current situation, analyze the macroeconomic conditions of their policies and economic environment, establish their own brand positioning and build their own brand names, and independent colleges should also understand the development of the same type of colleges found their strengths and weaknesses, and at the same time adapted to the general trend of education at home and abroad, updated their own positioning and timely adjustment of the brand to maintain vitality.

JC college's motto is just the best, refers to achieve a perfect realm, subtly JC students and teachers have a profound impact, when they embark on the job, to continue to implement this spirit, of course, will also have Good social effects, to attract more talents, for example, the Postal Savings Bank and JC College establish a long term close cooperative relations.

At the same time to be people-oriented, Maslow's hierarchy of needs, to meet the needs of teachers to achieve self-development, first of all, to develop long-term planning in line with the prospects of teachers, to provide teachers with a platform and road for their own development, regular training and training, So that teachers can see the school's humane care and respect for them so as to stimulate their long-term enthusiasm for work. At the same time, on certain festivals such as Women's Day and Labor Day, collective activities can be organized so that teachers in independent colleges can experience humane care, Foster teachers' feelings and sense of belonging to independent colleges, move people with emotion, and be better able to retain and attract talented people.

\section{Fifth, Identify Its Own Characteristics, Play Long Board Theory.}

Some independent colleges have opened many popular major or new major for admission, which led to the absence of teachers' teaching and forced them to continue looking for new teachers. This shows that we have to identify the characteristics of the school, have a clear understanding of the school and positioning, play the school's "long board" to attract more talents.

JC college, for example, in which the School of Business adhere to the school-enterprise cooperation, the development of many projects, set up a project consulting service center, so that experienced team of experts led teachers to participate in various research projects. For example, let experienced teachers become think tanks, for the development of government departments and 
companies' advice and suggestions. JC College, for example, has always been a close partner of Chengdu Qingbai River District and Sichuan Free Trade Zone. Such a strategy not only spreads the reputation of JC College rapidly, but also enables teachers to demonstrate and enhance their self-worth while serving local economic and social development, Alleviating the sense of job burnout, increasing teachers' sense of pride and accomplishment, and reducing the loss rate of talented people. Such a model has also attracted many outstanding talents.

\section{References}

[1] Fang Wang.Study on the Stability of Teachers in Independent Colleges from the Perspective of Psychological Contract [J]. Journal of Guangxi College of Education, 2013. (1): 61-62 (in Chinese)

[2] Zi-Zuan He, Mei-ZiCai, Can Can.Analysis on the Brain Drain under the Psychological Perspective of Teachers in Independent Colleges [J]. Manager, 2016 (28): 186.

[3] Xiao-Li Chen. Independent college student tutor status of the brain drain and countermeasures [D]. Sichuan: University of Electronic Science and Technology, 2010.

[4] Peng Zhao.Investigation on Teacher Loss in Chengdu Independent College from the Perspective of Incentive Mechanism [D]. Sichuan: University of Electronic Science and Technology, 2012.

[5] Jie Zhang. Current Independent College Teacher Team Building Countermeasures [J]. Journal of Yangtze University of Technology, 2003, (8): 22-24.

[6] Lu Yu. Independent College counselor job turnover and job burnout relationship [J]. Research in Economic and Social Science Research, 2016, (12): $465+467$.

[7] Jun-Xu Zhou. Industrial Cluster Talent Attraction and Its Impact Mechanism [D]. Wuhan: Huazhong University of Science and Technology, 2009.

[8] Ya-Ping Zheng, Wen-hui Luo, Yan Yang.Study on the Predicament and Countermeasures of Independent Colleges [J].Higher Education, 2016, (1): 49-51

[9] Lin-Sheng Xiao. Independent Workplace Teachers' Workload and Turnover Intention: An Intermediary Role of Job Satisfaction [J]. Higher Education Exploration, 2017,7 (7): 80-89.

[10] Fang Yu. Independent College Teachers' Job Satisfaction Research - Beijing Normal University Zhuhai Case Study [D]. Guangzhou: Guangzhou University, 2012.

[11] Ming-Xiang Xu. Research on Teacher Turnover Intention Based on Work Embedded Model [D].Yunnan: Yunnan University, 2011.

[12] Li Zhang. Independent college brand building and brand promotion [J]. Science \& Technology Information, 2009: $337+339$.

[13] Liu-Yun Qin. Independent College of brand building [D]. Guangxi: Guangxi Normal University, 2008.

[14] The 2016 National Education Development Bulletin [EB / OL]. [2017-07-10] .http: //moe.edu.cn//

[15] GuangMing Daily. West cited only difficult to solve problems [EB / OL]. [2017-11-02] .http: //epaper.gmw.cn//

[16] Wang Yi .BH college core brain drain factors and countermeasures [D]. Guangxi: Guangxi University, 2012.

[17] JiaOuYang. Improvement of Teachers' Drain in Independent Colleges --A Case Study of Guangzhou Independence College [J].Journal of Chifeng University (Natural Science), 2016, (8): 242-245.

[18] Wei-Guang Wei. Problems and Countermeasures of Brain Drain in Independent Colleges [J]. 
Contemporary Education Forum, 2011, (7). 